\title{
POSTGRADUATE STUDY IN UNCHARTED TERRITORY
}

\section{A COMPARATIVE STUDY}

\section{Brenda Leibowitz, Gina Wisker \& Pia Lamberti}

\section{INTRODUCTION}

Worldwide many mid-career professionals in a variety of professional occupations now undertake PhDs (Kiley 2015). In the UK for example, the drive for post-1992 universities to be more research-active, and the impetus from the Research Excellence Framework (REF) 2014, and upcoming REF 2020, has put the spotlight on recruiting, developing and motivating researchers, and encouraging academic staff already in posts to complete doctorates. And in South Africa, the achievement of a PhD is seen as a contribution to education for the public good, and an enhancement to the development of the knowledge economy (ASSAf 2010). This focus emphasises the importance of the $\mathrm{PhD}$ award for the academic career trajectory, and highlights the drive to encourage research-informed and research-led teaching and learning, with students as co-constructors of knowledge. The move underlines the vital role that mid-career researchers play in research productivity. The requirement that staff obtain PhDs can create pressures (Harley 2002), where staff have to become 'ringmasters', juggling the various institutional roles they have to play (Toews \& Yazedjian, 2007). It also can lead to 'creeping credentialism', where a PhD is seen as essential in academic life but might be a troublesome extra demand on a professional with qualifications in their own profession (Griffith 1995; Harley 2000; Harley \& Lee 1997; Henkel 1997; Henkel 2000).

We have labelled 'postgraduate study in uncharted territory' those studies being undertaken mainly by mid-career academic staff, which relate to their professional practice, and in disciplines considered professional or vocational, rather than as traditionally 'academic'. We see this as a relatively new area of exploration in terms of their own experiences of balancing academic roles, research discovery, theorising 
and transfer to professional practice. We have chosen the descriptor 'postgraduate study' rather than purely 'PhD study', since in South Africa certainly there remains a need to encourage lecturers, especially in technical and vocational domains, as well as previously disadvantaged institutions (Leibowitz, Bozalek, Van Schalkwyk \& Winberg 2015), to obtain master's degrees.

Earlier work on the doctoral learning journey (Wisker et al 2010) indicated the interrelatedness of issues concerning the conceptual cognitive work of a PhD, emotional and personal issues and identity, and the interface with institutional expectations and regulations. This framework is helpful in considering some of the challenges, joys and useful support processes which academic colleagues face when undertaking PhDs and master's studies.

This earlierwork (Wiskeretal 2010) produced evidence of the essential interrelatedness of intellectual/cognitive development, with ontology or a sense of being in the world, in this case being an academic researcher. It showed interrelatedness with personal and emotional issues, the professional world and pressures, and the institutional and regulatory demands of the $\mathrm{PhD}$. Postgraduate studies for this group of adult academic researchers also require more attention to particular genres of writing that prove challenging to the identities of those whose previous studies and teaching have been more practical, rather than text-based. These experiences can be understood using a lens informed by academic identities theories, since personal and professional identities intersect in writing (Wisker 2013). The PhD experiences of mid-career academic staff in professional practice-based disciplines and the factors that contribute to successful completion and transfer of knowledge into individuals' practice are little understood. Bitzer (2011) recommends investigating the personal, support, programme and institutional contexts of doctoral students. Motshoane and McKenna (2014) argue that postgraduate study success relies on institutional ethos and culture, while external professional culture informs practice.

The research project discussed in this chapter explored the PhD experiences of midcareer academic staff in professional practice-based disciplines at two universities, the University of Brighton, UK, and the University of Johannesburg, South Africa. Although contextually quite different, these institutions face similar challenges and opportunities in terms of such experiences, as do many other universities internationally, where academics from professional practice-based backgrounds are undertaking PhDs and master's mid-career. The project explores where and how the postgraduate students who are also academic colleagues experience challenges, joys and benefits and obtain the material, disciplinary and affective support they require. 


\section{EXPLORATORY CASE STUDY APPROACH}

The project was an exploratory and embedded case study (Yin 2003) comprising two separate studies, one in the UK and one in South Africa, where higher education policy changes led to lecturers in vocational or professional streams undertaking postgraduate study to improve their qualifications. The purpose of the comparative study is to consider issues of similarity and of concern in the two settings, in order to raise questions for further study. The research questions we set out to explore were:

- What are the professional, academic and personal benefits of participating in postgraduate study?

- What are the challenges?

- What material, disciplinary and affective resources do the students draw upon?

- What further research questions do these studies give rise to?

In addition to this exploratory research purpose, we were also motivated by the desire to derive recommendations for good practice in our two institutions. For the sake of brevity we do not report on the recommendations here.

The Brighton study utilised three sources of information, which were analysed for this case study. The Doctoral Learning Journeys project, described in detail in Wisker et al (2010) was rescrutinised for any focus on academic staff undertaking PhDs (noted as 1 in the data), a study on the support of academic staff who are also doctoral students writing their PhDs (Wisker 2013) (noted as 2 in the data), and new interviews conducted with academic staff undertaking PhDs (noted as 3 in the data).

The University of Johannesburg study comprised 11 semi-structured face-to-face interviews of approximately 45 minutes each, which focused on the experiences of established mid-career lecturers engaging in postgraduate study. The interviewees were lecturers in somatology, radiography, fashion design, industrial design, visual art, food technology and culinary arts. Interviewees were predominantly white and female, and in the 40-50 and 50-60 age brackets. Interviewees were selected on the basis of results of a survey that was sent out to lecturers who were placed in a staff qualifications programme (SQP) that entitled them to material and academic support, and which monitored their progress.

\section{CASE ONE: BRIGHTON UNIVERSITY}

\section{Setting}

Brighton University is a British post-1992 university. Its website (https://www.brighton. ac.uk/about-us/meet-brighton/index.aspx) describes the university thus: 


\section{PART THREE • CHANGING EXPECTATIONS OF POSTGRADUATE STUDENTS AND SUPERVISORS}

A part of Brighton since 1859, the university has been guided by its original ethos to become the diverse, multidisciplinary institution that it is today. With 20,700 students studying across five campuses in Brighton, Eastbourne and Hastings, the university community demonstrates civic responsibility across the south coast and beyond. We are defined by a commitment to social relevance, steering our curriculum and research projects away from the ivory tower and toward the fulfilment of public good as a trusted partner [...] We are the leading university for the professions, particularly medicine, nursing, engineering and pharmacy.

As with many other UK universities, Brighton encourages and supports academic staff to undertake professional development such as the Postgraduate Certificate in Higher Education and also master's and PhDs. Undertaking a PhD is not mandatory and indeed in some subjects, such as medicine, it might not always be the professional academic qualification of choice. In UK higher education, there is an enhanced drive for research achievement and outcomes as measured initially in the Research Assessment Exercise (RAE) and currently through the Research Excellence Framework (REF). The impending introduction of the 2015 Teaching Excellence Framework (TEF) which is aimed at ensuring and recognising excellence in teaching, enhancing widening participation, and raising student fees on the basis of TEF ratings, could mean changes to the balance of expectations and qualifications for academic staff whose roles are predominantly focused on teaching and higher education practice innovation. There is also a growing culture of developing links between research and teaching (Jenkins \& Healey 2005), which encourages academic colleagues to pursue appropriate research interests, build research into their teaching and support and encourage their students to become inquiring learners or researchers, and coconstructors of knowledge. A culture of research-informed teaching is widespread at Brighton University.

\section{Motivation for embarking on the study}

Although the policy environment requires academics to embark on $\mathrm{PhDs}$, the most commonly cited reasons for embarking on postgraduate study were to address issues and problems and to drive innovations in professional practice.

\section{Challenges}

Colleagues interviewed commented variously on the pressures to undertake research degrees. They talked about the difficulty of finding the time for both teaching and administration loads and a new research and writing load. Challenges to identity and confidence were noted where the academics felt they entered a different kind 
of academic career in which they felt less secure. Tensions were experienced in this journey and there was a palpable struggle with the use of theory, the research methods of PhD study and the thesis as a written genre. A student noted, "I have still struggled within the framework of the thesis; struggled to construct it and order the content within it" $(3, \mathrm{C})$. Another challenge when researching and teaching about practice is that the boundaries may become blurred in a way that is difficult to resolve. Interviewee 3, J reflected on his own situation as a teacher, professional and student:

Working in creative areas trying to push boundaries is demanding and writing about it as well as making practice presents its own set of challenges. One demanding question one supervisor asked of the postgraduate research group was how are you differing your work from your own professional practice and $\mathrm{PhD}$ ? That is, where is the research? How is it identifiable? $(3, \mathrm{~J})$

\section{Support}

In many instances the academics took advantage of support provided by the Centre for Learning and Teaching, mainly in the form of workshops, or they generated their own communities of support. Lecturer $J$ stressed the value of the support provided in his faculty:

I have been lucky enough to be in open, sharing environments in creative education, not a closed group. I practise my teaching in an open environment and I share knowledge openly as I think that's how knowledge should be shared, creative knowledge and practice is no exception ... Presentations of individual research in seminars, which are used as a method to get feedback on individuals specialist work are particularly useful, especially when nearing transfer exams or final vivas. $(3, J)$

Publication and support for publication were seen as positive by several academics interviewed. Benefits of this support were for social and collaborative learning and the encouragement of reflection:

The more postgraduate students interact with one another is useful for them to form connections with each other, and to promote a shared learning policy which helps reflection. It's only through deep reflection on experimentation/testing that the research student will make sufficient progress to proceed effectively and be able to write about the practice in the specialist area ... Having a support network over the years is very helpful. $(3, \mathrm{~J})$ 


\section{Benefits}

Several academics indicated that they felt this research had given them another identity, that of researcher. For some it enabled them to work with their like-minded colleagues, across their professions and practice and to experience the complexities of researching. The research work supported them in becoming more theorised in their dealing with professional problems, issues and innovations, and in learning to back up inquiry, innovation and evaluation with theory and research-based evidence. All of this helped develop confidence, particularly a voice articulating their ideas and practices - rather than leaving them somewhat inarticulate and only basing their arguments on opinion and experience as was the case previously. It enabled them to grow in stature with their colleagues and develop an identity as a researcher as well as a teaching academic.

For some, a celebratory recognition emerged: "Often the first publication serves as a catalyst to further work - I know I can!" Confidence and a sense of belonging to the academic community ensued:

A big learning experience for me has been that doing a doctorate is not a search for the truth but is really just taking part in a conversation. This doesn't stop me thinking that an 'expert' knows all of the answers and I suppose this is about confidence on my part ... So how can they know everything? And what I have to offer is just as important as theirs, and I suppose that is also a learning experience in that when I sit with the 'learned' in a conference I feel confident in challenging them as I now see myself as a peer. $(2, \mathrm{~K})$

Educators were able to explore and understand the relationship between their research, their practice and their teaching. An arts educator wrote:

My intellectual journey has incorporated a steep learning curve - bringing me to a greater theoretical understanding of the kind of relationship that exists between the framework for extended, research-based art tasks and theoretical, socially scientific PhD study. This has followed a constructivist approach. $(3, \mathrm{C})$

The $\mathrm{PhD}$ allowed $\mathrm{C}$ to learn via crossing disciplinary and practice boundaries. It led to a greater understanding of the relationship between his teaching role and his professional life:

It liberated me in the reassurance that I was wilfully and intentionally making meaning of the processes and offering myself permission to construct for research purposes. They suggested that meanings could become personalised and discoveries established and shared in the educational context. These meanings crossed borders and blurred boundaries between professional thinking according to expected role in 
the classroom and my own personal beliefs. An ontology which allowed my identities outside of teaching roles to be integrated into the teaching classroom and studio was and still is a troubling compulsion. It became necessary to allow my various behaviours to collide and create a more vulnerable educator. $(3, \mathrm{C})$

One of the very interesting issues is the nature of using theory which has enabled this researcher to theorise the research and also the self and academic identity as a researcher.

\section{CASE TWO: THE UNIVERSITY OF JOHANNESBURG}

\section{Setting}

The University of Johannesburg (UJ) is an urban higher education institution which received its current organisational form as a 'comprehensive university' in 2005. It is the product of a government-initiated policy to merge institutions: in this case, a traditional academic institution, a technikon that offered technical and vocational qualifications, and two satellite campuses of a distance-teaching institution that offered traditional fields, including education. The result was that when faculties from the antecedent institutions were merged, some had both traditional academic and technical/vocational programmes. The senior management rapidly set out to unify the campuses into a single institution that is innovative, relevant and competitive. More recently it has set its sights on improving its position in world ranking systems. In 2009 all permanent and fixed-term teaching staff without master's qualifications were instructed to register for further study. This was not the result of governmentled fiat, but there was certainly pressure in the country, as well as internationally, to increase the number of academic staff with master's and doctorates. As a form of support, the Staff Qualifications Programme (SQP M) was initiated by executive management, to be managed by the Centre for Professional Academic Staff Development. The support provided was in the form of a series of generic and interdisciplinary workshops and funding for up to three months for staff replacement while master's dissertations were completed. By mid-2015, 44.4\% of the permanent staff had doctorates and $42.3 \%$ had obtained master's qualifications. A small percentage of lecturers are still completing their master's studies, and those lecturers unwilling to study further have left the university's employ. The success of SQP M resulted in the introduction of a similar optional support programme for lecturers engaging in doctoral study (SQP D).

UJ is comparatively well resourced in the South African context in terms of both funding and facilities - the latter especially in the technical and vocationally oriented 
faculties. Despite the aim to increase the number of academics with master's and doctorates and to improve its position on ranking systems, it remains committed to the teaching function. This commitment to the teaching function can be attributed to its rapid deracialisation and its stated commitment to support students who are underprepared for university study. By way of explanation, two out of the three legacy institutions catered for white students from middle- and upper-class backgrounds. By 2015 the composition of the institution was representative of the population of the country in terms of race. There were already approximately 50000 students and, more importantly, the student-lecturer ratio was one of the highest in the country, leading to large classes in certain faculties. In the technical/vocational fields, a model persists from the pre-merger times, which demands much contact time and a full timetable for students, as well as a high teaching load for academics.

\section{Motivations for embarking on postgraduate study}

As indicated by the interviewees, there were a variety of reasons for embarking on the study: to comply with institutional directives; for promotion and mobility purposes; and for self- and professional development. Only four of the interviewees admitted that their primary motive for doing a postgraduate qualification was that the institution had compelled them to do so, but in reality, the number who felt compelled to do so might have been higher.

\section{Challenges}

While all 11 interviewees acknowledged the benefits of undertaking further study, the challenges they experienced dominated most of the interviews. The disciplinary and departmental affiliations required creative manoeuvres for many of the interviewees, who could not study further in their own fields because these were not in themselves stable knowledge fields, or because doctoral qualifications were not offered by the faculties in which they were located (Interviewee 1.6). Some lecturers sought supervisors elsewhere and registered at other universities due to the scarcity of qualified supervisors in their fields. This resulted in their having to pay fees and to travel to another institution, thus creating further time demands. A second difficulty arising out of disciplinary affiliation is that those who chose topics outside of their familiar fields had significant gaps in terms of prior knowledge and academic practices required in the new disciplinary field. This posed considerable challenges to their sense of self and academic identity, as indicated by Interviewee I.8: "I found it very difficult to do a research report ... without any of the previous underpinning knowledge to bring that forward." 
Making time to study as well as balancing workload and family commitments posed challenges to many of the interviewees. This state of affairs was aggravated by contexts in which the heads of department were either not sympathetic to the need for time to study, or where there were simply too few lecturers for time off to be feasible. The degree of support from heads of department or deans varied significantly, from one faculty where the departments were consistently supportive and encouraging, to one which was unhelpful. Interviewees in the latter faculty attributed this challenge to issues such as gender, race, age, and importantly, lack of academic status. It is clear, therefore, that departmental culture and teaching and learning regimes are of great significance (Knight, Tait \& Yorke 2006).

As in the Brighton study, challenges to identity and confidence were noted. These challenges were influenced by how the lecturers thought others perceived them, or how they perceived themselves. Some interviewees found their colleagues to be dismissive of their potential because of their perceived lack of academic standing, their age, race or gender. Of particular concern was the point made by some interviewees that they were not respected because their professional practice field was not of high status or specifically academic. Several over-compensated by conducting studies that were more academic or 'blue skies', than applicational. One colleague persisted with a more applicational study despite her belief that this would not be valued in her faculty:

Well, look, in the faculty of science they would actually even reword the promotion policy in such a way that my $\mathrm{PhD}$ is probably not even going to count ... I weighed it up against what my personal ambition is and what would make the most difference to my industry and also to my students. (I.8)

Some felt isolated while studying, as families or friends did not understand what they were going through:

From a personal point of view, it had an incredible impact on relationships in general at home. Because it's very much like distance occurs for extended periods of time, but nobody really understands what you're doing. And the reasons why you're doing it. I don't even think they're interested. (I.2)

This statement could equally have been made by postgraduate students who were not from more professional or vocationally oriented environments; but the vocational/ professional location did influence a sense of isolation in the workplace:

... there were very, very, very few people that had master's. And those that did have master's had come from an original university environment. 
Not from - their undergraduate stuff had not come from a technikon. So they didn't understand. (I.7)

Some simply did not see themselves as academic, or felt 'selfish' to be spending time on their own studies rather than using their time to develop their students and younger colleagues (I.7).

\section{Support}

Interviewees gained support from partners and workmates. Two derived support from working alongside colleagues in a similar situation, developing a sense of camaraderie and materially helping each other (Interviewees 7 and 8). In some instances, the dean or head of department provided material or moral support. Gratitude was also expressed for national and institutional initiatives, which provided funding for time off or travel, or in the case of the SQP, training sessions. These developmental workshops offered research skills that the staff felt they needed, and exposure to colleagues from other disciplines in the same situation. This approach had the effect of reducing intellectual isolation. Good supervision was another form of support that was mentioned. Interviewees were also enabled by their personal characteristics and life circumstances - what Margaret Archer, in her study on the role of agency, would refer to as "personal emergent properties" (Archer 2000). Prior learning played an important role in the resources that some of the interviewees could draw upon; for example Interviewee 8, who had studied education earlier in her life, did her master's in education, rather than her home discipline, hospitality studies. Motivation was a trait which featured strongly in the interviews of all those engaged in PhD study: Interviewee 1 referred to 'tenacity'. Interviewee 4 created her own support community, which met in a coffee shop close to her apartment, and she regularly drew on the support of the university's Writing Centre.

\section{Benefits}

The interviewees acknowledged considerable benefits for having embarked on postgraduate study. These benefits were not only intellectual and cognitive, but also affective and identity-related. Three of the lecturers (Interviewees 1, 7 and 8) indicated that their studies had informed the way they conducted curriculum development:

I've changed how I teach marketing and I've changed how I teach HR. Applied, but it's based on theory and theorists. So because of my experience of this, I can make it practical for the students. I help them understand that you can't have this free-floating content; it's got to be wedged in some theoretical approach. And I have changed the way I 
teach, yes. And the way I examine. I move from a theoretical perspective to an applied perspective. So I will combine them. (I.7)

Two felt that through their studies they could see the relevance of their discipline and several felt more excited about their teaching. There were benefits to do with mobility and enhancing career profile, for example, a mid-career male lecturer whose research led him to make connections with people in the industry and to network internationally:

We're doing research in technological development ... it's sort of aligned with what I'm doing in the PhD and then I've got offers from the university, from the department, from government. (I. 1)

Interviewees appreciated being exposed to new knowledge, and becoming more critical. Their transcripts provided images such as 'embarking on a journey' (I.5) and being introduced to a 'sweetie shop' of knowledge and concepts (I.8).

With regard to their professional identity, several felt a sense of pride and achievement, becoming more 'confident' (I.4) and stating that their 'sense of self' (I.6) had been enhanced. It is not surprising that several academics who had felt unconfident academically now saw themselves as intellectually more capable, as indicated by Interviewee 1.2: "There is a certain amount of personal achievement of having done it whereas you go through the entire time thinking you're the one that isn't capable."

The increased relevance and deepening sense of being able to contribute was not only felt in relation to teaching and the discipline. For three of the lecturers their fieldwork and dissemination activities led them to learn about diverse communities in South Africa and to believe that they were able to make a contribution to South African society:

But my fieldwork I loved. I loved interacting with people, knowing that there are places here you can actually be ethical and make a difference ... So it was great to be humble and listen to indigenous knowledge and not just assume that they don't know better ... And it's making a difference and that is so uplifting and empowering because you're doing real stuff. It's real-world and you are creating a real solution. It's not just something that's theory. It's applying that theory. (I.3)

\section{DISCUSSION}

A comparison of the two studies reveals very similar issues coming to the fore. In both cases national policy pressure was felt by individuals, who were further prompted to study - in the UJ case by institutional pressure as well. Challenges in both cases pertained to practical issues such as time management; identity (influenced in 
the South African case by social categorisations such as race and gender); and academic, research-related practices such as academic writing. In both studies interviewees reported growing in relation to research skills, disciplinary knowledge and, significantly, in relation to their teaching. In both instances formal institutional support featured, as well as informal support from self-generated communities of practice and departmental cultures. The study supports the findings by earlier work by Wisker et al (2010) on the interrelatedness of intellectual/cognitive work with a sense of being in the world and identity. Bitzer's (2011) depiction of the ecology in which postgraduate students work, comprising personal, support, programme and institutional contexts, is found to be relevant for lecturers who teach in professional and technical fields, who study while they teach. Institutional culture and ethos, as suggested by Motshoane and McKenna (2014) are indeed relevant, but more so at the level of department and faculty rather than the institution as a whole.

Both studies suggest it is worthwhile to require vocational and technical lecturers in higher education to study further. This is despite the challenges in terms of time and workload, isolation and identity. The benefits accrue in relation to individual academic identities as well as the professional practice of the lecturers in their three roles: teaching, research and community engagement. The data point to the value of national and institutional support mechanisms, but also to the need to influence the culture in departments and in order for academics to learn informally from colleagues in their departments or in 'workgroups' (Knight et al 2006), thus emphasising the role of the head of department in encouraging a culture of learning and of support. Staff in the technical and vocational fields should be encouraged to study further, at the level of master's and PhDs. However, care should be taken not to disparage the more applicational and less directly academic knowledge practices that might be highly valued by industry and community interests. The South African study in particular suggests that academics teaching professional/vocational courses benefit from both types of knowledge practice, and should not be straitjacketed into either stream.

\section{CONCLUSION}

The studies discussed in this chapter provide insights about the experiences of mature professionals who take on the role of the student once more. These insights could be drawn on to inform institutional practice and policy. The preliminary findings of this ongoing research study indicate that it is worth continuing to explore the experiences of academic staff that pursue postgraduate studies in uncharted territory. 
As was indicated in the introduction to this chapter, these two studies are intended to suggest further areas of research on postgraduate supervision. Two important themes highlighted for further study are those of academic identity and departmental or workgroup culture. Important questions which were raised and which could benefit from a deepened analysis across country settings are: What is the relationship between professional/vocational practice, teaching practice and postgraduate research? What are the risks as well as the opportunities? How is a culture and practice of support nurtured in departments or work groups where such a culture does not exist? What kinds of postgraduate study (academic, applicational, in own fields or across disciplinary fields) should be encouraged - and, indeed, should lecturers working in the professional and vocational fields be steered in any particular direction at all?

\section{REFERENCES}

Archer M. 2000. Being human: The problem of agency. Cambridge: Cambridge University Press.

ASSAf (Academy of Science of South Africa). 2010. The PhD study: An evidence-based study on how to meet the demands for high-level skills in an emerging economy. Consensus Report. Retrieved 1 February 2015. http://www.assaf.co.za/wp-content/ uploads/2010/1 1/40696-Boldesign-PHD-small.pdf.

Bitzer E. 2011 . Doctoral success as ongoing quality business: A possible conceptual framework. South African Journal of Higher Education, 25(3):425-443.

Brighton University. nd. https://www.brighton.ac.uk/about-us/meet-brighton/index.aspx (retrieved 30.07.2016)

Griffith J. 1995. Research assessment: As strange a maze as e'er men trod. Report No 4. London: Council for Academic Freedom and Academic Standards.

Harley S. 2000. Accountants divided: Research selectivity and academic accounting labour in UK universities. Critical Perspectives on Accounting, 11:549-582.

Harley S. 2002. The impact of research selectivity on academic work and identity in UK universities. Studies in Higher Education, 27(2):187-205.

Harley S \& Lee FS. 1997. Research selectivity, managerialism, and the academic labour process: The future of non-mainstream economics in UJ universities. Human Relations, 50:1425-1460.

Henkel M. 1997. Academic values and the corporate enterprise. Higher Education Quarterly, 51:134-143.

Henkel M. 2000. Academic identities and policy change in higher education. London: Jessica Kingsley.

Jenkins A \& Healey M. 2005. Institutional strategies to link teaching and research. York: The Higher Education Academy. 


\section{PART THREE • CHANGING EXPECTATIONS OF POSTGRADUATE STUDENTS AND SUPERVISORS}

Kiley M. 2015. Troublesome knowledge and the professional, mature-age PhD candidate. Paper presented at EARLI conference, Limassol, Cyprus. http://www.ee.ucl. ac.uk/ mflanaga/abstracts/TC14Abstract1 0.pdf (retrieved 31.07.2016)

Knight P, Tait J, \& Yorke M. 2006. The professional learning of teachers in higher education. Studies in Higher Education 31 (3):319-339.

Leibowitz B, Bozalek V, Van Schalkwyk S \& Winberg C. 2015. Institutional context matters: The professional development of academics as teachers in South African higher education. Higher Education, 69:315-369.

Motshoane P \& McKenna S. 2014. More than agency: The multiple mechanisms affecting postgraduate education. In: E Bitzer, R Albertyn, L Frick, B Grant \& F Kelly (eds). Pushing boundaries in postgraduate supervision. Stellenbosch: SUN MeDIA. 185-202.

Toews M \& Yazedjian A. 2007. The three-ring circus of academia: How to become the circusmaster. Innovative Higher Education, 32:113-132.

Wisker G. 2013. Articulate - writing, editing and publishing our work in learning, teaching and educational development. Innovations in Education and Teaching International, 50(4).

Wisker G, Morris C, Cheng M, Masika R, Warnes M, Trafford V, Robinson G \& Lilly J. 2010. Doctoral learning journeys report. http//www.heacademy.ac.uk. (retrieved 31.07.2016)

Yin RK. 2003. Case study research: Design and methods (3rd ed). Thousand Oaks, CA: SAGE. 